\title{
Correlation between mass loss on the cavitation erosion and the fatigue stress level for a martensitic stainless steel
}

\section{Correlación entre la pérdida masiva en la erosión por cavitación y el nivel de fatiga por estrés en un acero inoxidable martensítico}

\author{
Mircea Vodă ${ }^{1 a}$, Alberto Pertuz-Comas ${ }^{2}$, Viorel Aurel Şerban ${ }^{1 b}$ \\ ${ }^{1}$ Faculty of Mechanics, "Politehnica” University Timisoara, Bd. Mihai Viteazul nr. 1, 300222 Timisoara, Roumania. \\ Email: ${ }^{a}$ mircea.voda@upt.ro, ${ }^{b}$ viorel.serban@mec.upt.ro \\ ${ }^{2}$ School of Mechanical Engineering, Universidad Industrial de Santander, Bucaramanga, Colombia. \\ Email: apertuzc@uis.edu.co
}

Received: 20 September 2017. Accepted: 27 January 2018. Final version: 3 June 2018.

\begin{abstract}
The effect of fatigue on the cavitation erosion was examined for a martensitic stainless steel used in the manufacture of the blades for the bulb turbines of the "Iron Gates II" Power Plant turbines. For the cavitation tests, two kinds of specimens were manufactured: from the original material (which was not subjected to fatigue) and samples of materials that were subjected to fatigue cycles with different amplitudes (from 170 to $255 \mathrm{MPa}$ ). It was observed that fatigue increases the tendency of cavitation erosion and thus, seems like a cumulative damage. The analysis of the cavitation erosion was done considering simultaneously the mass loss of the time dependence, the surface roughness and the modifications to the microstructure of the specimens. For the material previously subjected to fatigue cycles, the final mass loss (after 150 minutes of cavitation exposure) increases approximately by $30 \%$ and the depth of penetration by $25 \%$. In the microstructural analyses, numerous cracks at grain boundaries were observed. Finally, a mathematical model for the dependence of mass losses with the applied stress was developed.
\end{abstract}

Keywords: cavitation erosion; cumulative damage; fatigue; stainless steel; water turbine.

\section{Resumen}

Se examinó el efecto de la fatiga en la erosión por cavitación para un acero inoxidable martensítico utilizado en la fabricación de palas para las turbinas Bulbo de las turbinas de la Planta de Energía "Iron Gates II." Para las pruebas de cavitación se fabricaron dos tipos de especímenes: tanto el material original (que no estaba sometido a fatiga) como muestras de material que se sometieron a ciclos de fatiga con diferentes amplitudes (de 170 a $255 \mathrm{MPa}$ ). Se observó que la fatiga aumenta la tendencia de la erosión por cavitación y por lo tanto, parece un daño acumulativo. El análisis de la erosión por cavitación se realizó teniendo en cuenta simultáneamente la pérdida de masa de la dependencia del tiempo, la rugosidad de la superficie y las modificaciones en la microestructura de las muestras. Para el material sometido previamente a ciclos de fatiga, la pérdida de masa final (después de 150 minutos de exposición a la cavitación) aumenta aproximadamente un $30 \%$ y la profundidad de penetración con un $25 \%$. En los análisis microestructurales se observaron numerosas grietas en los límites de los granos. Finalmente, se desarrolló un modelo matemático para la dependencia de las pérdidas de masa con el estrés aplicado.

Palabras clave: acero inoxidable; daño acumulativo; erosión por cavitación; fatiga; turbina de agua.

ISSN Printed: 1657 - 4583, ISSN Online: 2145 - 8456, CC BY-ND 4.0 (c) (i) $९$

How to cite: M. Vodă, A. Pertuz-Comas, V. A Şerban, "Correlation between mass loss on the cavitation erosion and the fatigue stress level for a martensitic stainless steel," Rev. UIS Ing., vol. 18, no. 1, pp. 11-20, 2019. doi: 10.18273/revuin.v18n1-2019001 


\section{Introduction}

The production of hydroelectric power plants represents a significant percentage of electric power obtained all over the world. Moreover, the electric energy generated by hydroelectric turbines constitutes a great portion of the quantum of electric energy. For the energy system maintenance, it is important that each unit of turbines runs according to optimal parameters for the exploitation in an estimated period. Moreover, the cases which can involve repair works are due to the cavitation erosion of the material of the blades or of the turbine runner. The variable and repetitive loads in time, produced by the hydrodynamic mass, and the inertia with the related moments applied to the runner of the turbine have an effect on the phenomenon of material fatigue. Slip bands develop as the number of cycles increases and forms various agglomerations. Thus, the courses of slip and the geometries are dependent on the structure of the material and the conditions of load. In the bands of slip, cracks are launched, and they join when the local concentration of effort appears [1]. The cracks can also be formed on the grain boundaries if the effort is rather large. In addition, there are other sources of cracks such as boundaries of the blocks, inclusions and precipitates of grains of the secondary phases. The cracks usually appear on surface and in surface layers where the marks of the treatment, grain boundaries, wells, small defects of the material or the discontinuities microphone caused by lines of slip can occur. The element exposed the most to fracture is, in fact, the blade, but at the same time, it can be affected the most, even harmfully, by cavitation. During the cavitation erosion, the following phenomena take place: the initial roughness of the surface is modified by pits [2]; afterward, the pits develop into microcracks [3].
Roughness also accelerates the propagation of cracks and makes the separation of the material particles easy [4]. The bands and the alleged ways belong to the most significant characteristics of the fatigue failure [1]. During the cavitation erosion, small local plastic constraints influence the formation of the cracks similar to fatigue fissures. The propagation of crack causes displacements and pert material particles. The cracks usually develop in the parallel direction, perpendicular to the surface, when a certain depth is obtained. It means that incubation has been achieved and the loss of mass of the material starts [5]. In the literature, we found studies about the relation between the resistance of cavitation erosion of materials and their fatigue resistance [6] and about the resistance of cavitation erosion under the influence of creep-fatigue [7, 8]; nevertheless, any information upon the cumulative effect of these two damages was not addressed. In this article, we propose an experimental research in order to determine the effect of the fatigue on the cavitation erosion.

\section{Experimental Process}

\subsection{The material}

The material under investigations was taken directly from a blade used at the Power Plant Iron Gates II. The producer certificate indicated that the material is the stainless steel G-X5CrNi13.4. According to EN 1008-3, the chemical composition and the mechanical properties of this material are those presented in Tables 1 and 2 . The chemical composition determined in our laboratory is presented in Table 3 and reveals important deviations for the prescribed content of $\mathrm{Ni}, \mathrm{Mo}$ and $\mathrm{Cu}$.

Table 1: Chemical composition of G-X5CrNi steel 13.4

\begin{tabular}{|l|l|l|l|l|l|l|l|l|l|}
\hline $\mathrm{C}(\%)$ & $\mathrm{Mn}(\%)$ & $\mathrm{Si}(\%)$ & $\mathrm{P}(\%)$ & $\mathrm{S}(\%)$ & $\mathrm{Cr}(\%)$ & $\mathrm{Ni}(\%)$ & $\mathrm{Mo}(\%)$ & $\mathrm{N}(\%)$ & $\mathrm{Fe}(\%)$ \\
\hline 0,05 & 0,223 & 0,442 & 0,012 & 0,023 & $12-14$ & $3,5-4,5$ & $0,3-0,7$ & 0,02 & Rest \\
\hline
\end{tabular}

Table 2. Mechanical properties of the steel of G-X5CrNi 13.4

\begin{tabular}{|c|c|c|c|c|}
\hline $\begin{array}{c}\rho \\
\left(\mathrm{kg} / \mathrm{dm}^{3}\right)\end{array}$ & $\begin{array}{c}\mathrm{R}_{\mathrm{e}} \\
\left(\mathrm{N} / \mathrm{mm}^{2}\right)\end{array}$ & $\begin{array}{c}\mathrm{R}_{\mathrm{m}} \\
\left(\mathrm{N} / \mathrm{mm}^{2}\right)\end{array}$ & $\begin{array}{c}\text { elongation } \\
(\%)\end{array}$ & $\mathrm{HV} 10$ \\
\hline 7,7 & 520 & 730 & 14,8 & 260 \\
\hline
\end{tabular}

Table 3. Determined chemical composition of G-X5CrNi13.4

\begin{tabular}{|l|l|l|l|l|l|l|l|l|l|}
\hline $\mathrm{C}[\%]$ & $\mathrm{Mn}[\%]$ & $\mathrm{Si}[\%]$ & $\mathrm{P}[\%]$ & $\mathrm{S}[\%]$ & $\mathrm{Cr}[\%]$ & $\mathrm{Ni}[\%]$ & $\mathrm{Mo}[\%]$ & $\mathrm{Cu}[\%]$ & $\mathrm{Fe}[\%]$ \\
\hline 0,077 & 0,271 & 0,307 & 0,014 & 0,025 & 13,5 & 2,34 & 0,3 & 0,95 & Rest. \\
\hline
\end{tabular}




\subsection{Fatigue tests}

The fatigue tests were made using the machine Instron 8516 pennies the tensile stress. Figure 1 gives the geometry of the sample. The samples were subjected to the cyclic loading at ambient temperature with sinusoidal waves of a frequency of $20 \mathrm{Hertz}$. For all the tests, the stress ratio (Smin/Smax) was the same one, namely 0.5. The stress applied ranged from 170 to $500 \mathrm{MPa}$; thus, the cycles included the value of $90 \%$ of the elastic limit of the tested steel. The ranges of the forces and the amplitudes of stresses used in the fatigue tests are given in Table 4.

Table 4. Conditions of the tests

\begin{tabular}{|c|c|c|c|c|}
\hline Number of the test & 1 & 2 & 3 & 4 \\
\hline Interval of force $[\mathrm{kN}]$ & $60-30$ & $70-35$ & $80-40$ & $90-45$ \\
\hline Amplitude of the stress $\Delta \sigma[\mathrm{MPa}]$ & 170 & 198 & 226 & 255 \\
\hline
\end{tabular}

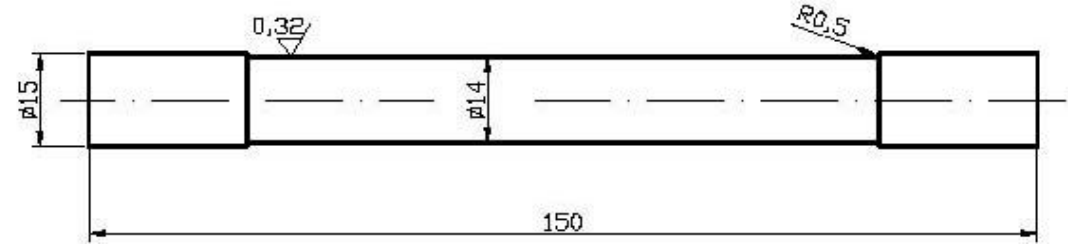

Figure 1. Geometry of the sample for the uniaxial fatigue test

The fracture was not always in the central zone of the sample, but it was all the time a fatigue failure type (see
Figure 2). The diagram of test sample selection for the test of cavitation is shown in Figure 3.

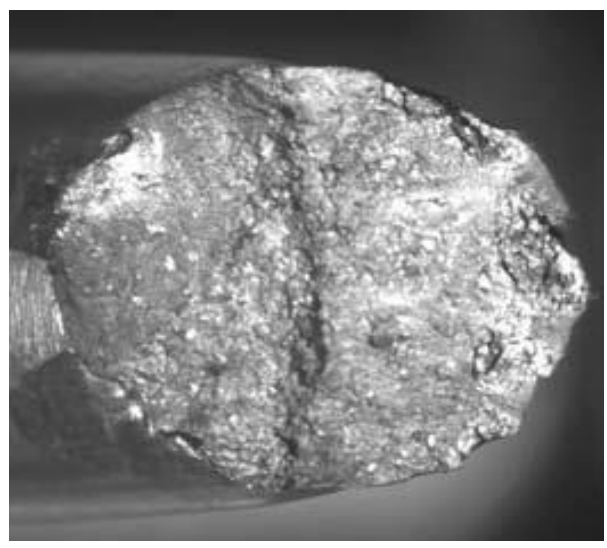

Figure 2. Example of fracture

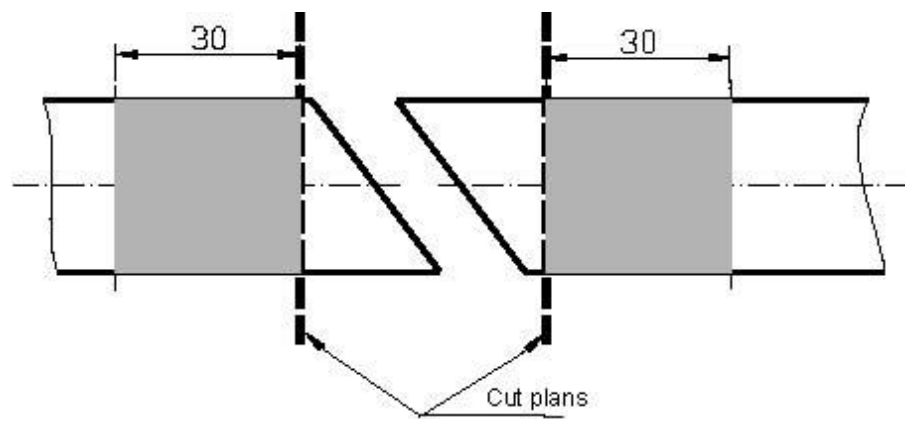

Figure 3. Diagram of test sample selection for the test of cavitation 


\subsection{Cavitation erosion tests}

Two types of samples were examined: without fatigue and after fatigue.

A vibratory apparatus with a magnetostrictive oscillator was used according to the standard testing method G32 of test of ASTM [12]. This testing method produces cavitational damage on the surface of a sample vibrated at high frequency while it is immersed in a liquid. The vibratory movement and the adherence of the liquid to the surface generate a cloud of cavitation bubbles which implodes on the surface of the specimen and causes the erosions. Although the cavitation mechanism in this method differs from that occurring in hydraulic machinery [9], it is thought that the nature of the mechanism of material damages is basically similar. The method thus offers a relative simple and controllable test which can be employed to compare the resistance of cavitation erosion of various materials in order to study in detail the nature and the progress of the damage to a given material, or by changing some of the conditions of test in order to study the effect of the variables of test on the produced damage. Our reason to employ it was to check the differences between the samples and to show the rate of the cumulative damage.

The samples of cylindrical shape have a diameter of 14 millimeters and the surface roughness Ra $0.4 \mu \mathrm{m}$. The vibrations are produced with a frequency of $7 \pm 3 \% \mathrm{kHz}$. The characteristics of the device at this frequency are: one period of vibration $\mathrm{T}=14.28 \times 10-5(\mathrm{~S})$, pulsation of oscillations $\omega=43.98 \times 10-3$ (s-1) and the maximum of the sonic pressure p S max $=29.187$ (bar). The liquid used during testing was water at the temperature of $21 \pm 1^{\circ} \mathrm{C}$. The two types of samples were eroded for 5 minutes and then, 15 minutes, and the duration increased 15 minutes until a maximum duration of 150 minutes. After the exposure to cavitation, the sample tested was removed from the vibratory tube bar and was weighed using an analytical balance having a sensitivity of 0,01 $\mathrm{mg}$. Finally, the rate of cavitation erosion was obtained (it is the loss of mass divided by the duration of the test). The eroded surface was analyzed using the optical microscope and the scanning electron microscope. Also, measurements of the surface roughness were made with a laser profilometer (Perthometer S3P, Mahr Perthen, France); the profiles and the values Ra were obtained.

\section{Results and discussions}

The structural investigations made with the optical microscope and the scanning electron microscope confirm the opinion of other authors [6] about the similarity between the phenomena in cavitation and fatigue failure. The time variable and repetitive loads applied to the turbine blades, generated by the hydrodynamic mass and inertia forces with the afferent moments, lead to the fatigue phenomenon. The slip band develops as the number of cycles increases and forms various agglomerations and bunches which finally, produces the particles rupture.

The fracture aspect shows that the eroded surface presents the same characteristics (Fig. 4 a, b) as in the fatigue fracture case. The specific peculiarities of the cavitation erosions are given by the surface quality; the impurities containing the precipitates and secondary phase at the grain boundaries were the places from where the cracks started. In Fig. 5 a and b it can be seen that the crack initiated at the surface and spread perpendicular to it. After a certain depth, some cracks receive a direction parallel to the surface. The cracks start from the erosion pits formed at the surface. The tested material has a relative hard structure ( $35 \ldots 40 \mathrm{HRC})$, and we think that the cause of the rupture initiation is the eutectic inclusions and the second phase. For example, in Fig. 6, the rupture was caused by a chrome carbide inclusion.

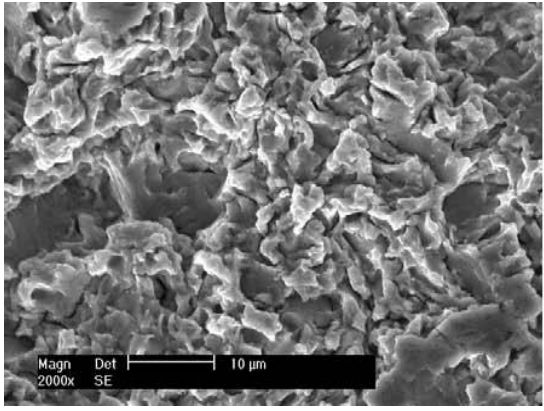

a) Image SEM

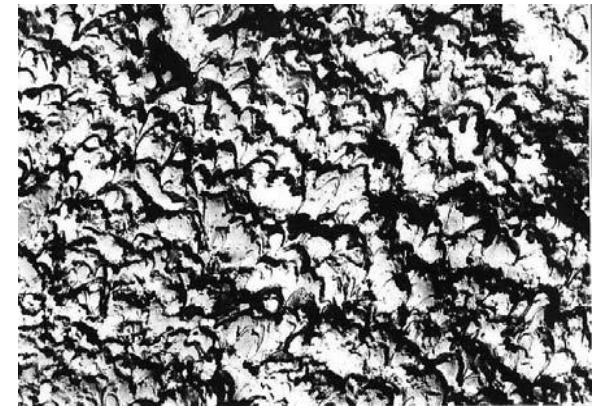

b) Image TEM

Figure 4. The eroded surface without fatigue 


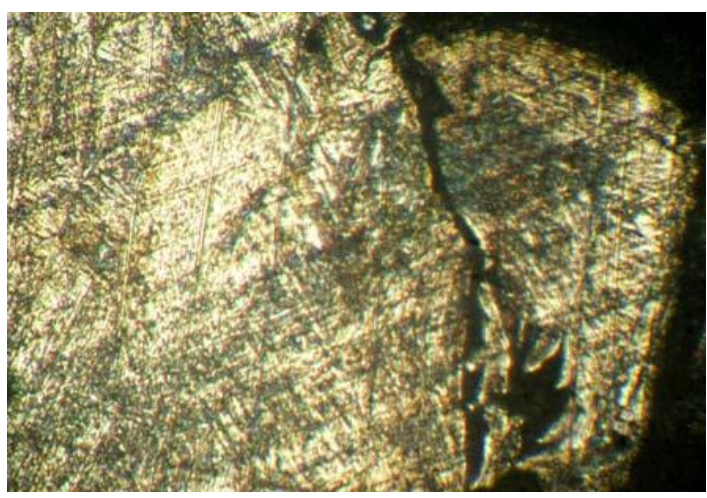

a) OM 500x

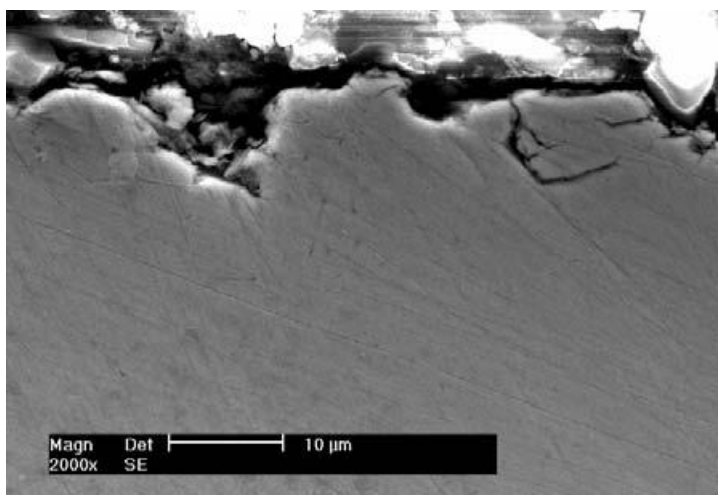

b) Image SEM

Figure 5. The crack initiation on the surface

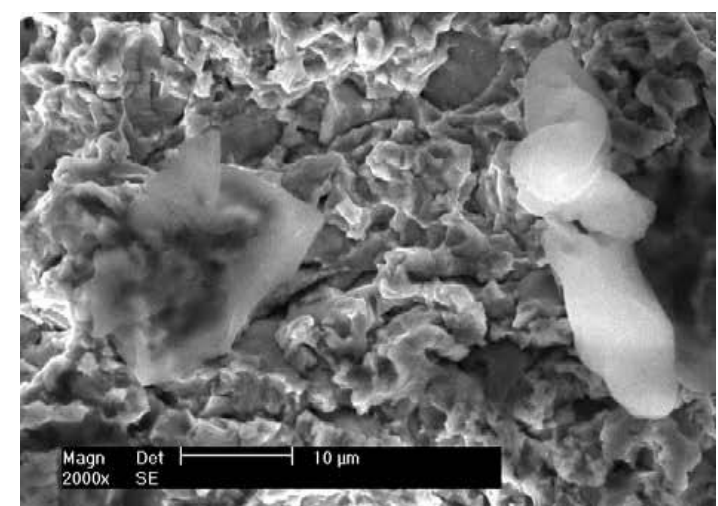

Figure 6. Crack induced by a chrome carbide inclusion

The penetration of cavitation erosion was analyzed using the measurement of external of roughness. Since the displacement of the sensor of the profilometer cannot exceed 10 millimeters, we took radial measures starting from the surface not eroded (of the border) in the center of the sample. We noted that the penetration depth of cavitations is most significant for samples having cycles of fatigue. Figure 7 displays the results of measurement for the case $\Delta \sigma=198 \mathrm{MPa}$. Ra exterior roughness is with $2,21 \mu \mathrm{m}$ larger in the case of the sample tested with fatigue and roughness $\mathrm{Rz}$ is $13 \mu \mathrm{m}$ greater.

One can also see that the depth of the eroded surface is almost constant for the whole sector in the case of sample with cycles of fatigue carried out, whereas for the case without fatigue, the depth is not homogeneous.

Taking into account the evolution of the experimental results (the mass loss in time), we examined several forms of analytical functions (exponential, logarithmic curve, polynomial), and we maintained the one which gave the best correlation for the loss of mass [ 13 ]. The experimental results were regulated. The best correlation was obtained with the exponential functions described below:

- the loss of mass in time:

$\mathrm{m}=\mathrm{A} \sum_{i=1}^{n} m_{i} \cdot t \cdot\left(1-e^{-B \cdot t}\right)$

where: $\mathrm{m}$ - the loss of mass [ $\mathrm{mg}$ ];

A - the scale parameter of the curve;

$\mathrm{B}$ - the form parameter of the curve;

$\mathrm{T}$ - time [ $\min$ ].

In Figure 5, the stringer of the experimental results for the analytical relation selected is illustrated. The synthesis of the evolution of the results accepting the analytical model is given in Table 5. 


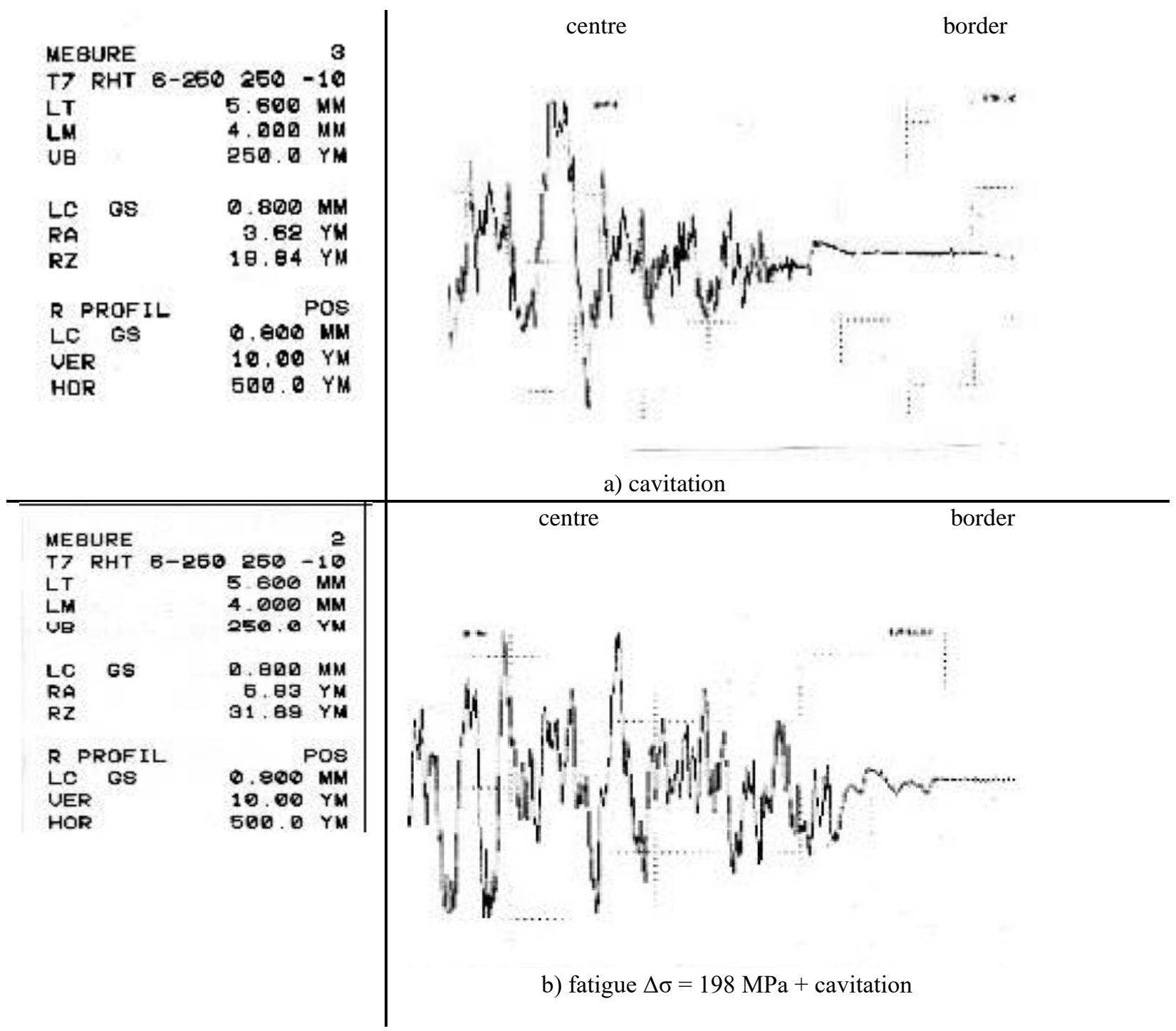

Figure 7. Results of measurements of the roughness of surface

Table 5. Evolution of the parameters and the mass loss

\begin{tabular}{|c|c|c|c|c|c|}
\hline Parameter & \multicolumn{5}{|c|}{ Type of test sample } \\
\hline & no fatigue & $\begin{array}{c}\text { fatigue } \\
60-30[\mathrm{KN}] \\
\Delta \sigma=170 \mathrm{MPa}\end{array}$ & $\begin{array}{c}\text { fatigue } \\
70-35[\mathrm{KN}] \\
\Delta \sigma=198 \mathrm{MPa}\end{array}$ & $\begin{array}{c}\text { fatigue } \\
80-40[\mathrm{KN}] \\
\Delta \sigma=226 \mathrm{MPa}\end{array}$ & $\begin{array}{c}\text { fatigue } \\
90-45[\mathrm{KN}] \\
\Delta \sigma=255 \mathrm{MPa}\end{array}$ \\
\hline A & $1,703 \cdot 10^{-4}$ & $2,053 \cdot 10^{-4}$ & $2,243 \cdot 10^{-4}$ & $2,411 \cdot 10^{-4}$ & $2,706 \bullet 10^{-4}$ \\
\hline B & 0,053 & 0,053 & 0,053 & 0,053 & 0,053 \\
\hline $\begin{array}{l}\text { Cumulated mass } \\
\text { loss [ mg ] }\end{array}$ & 26,29 & 30,78 & 33,64 & 36,16 & 40,57 \\
\hline
\end{tabular}




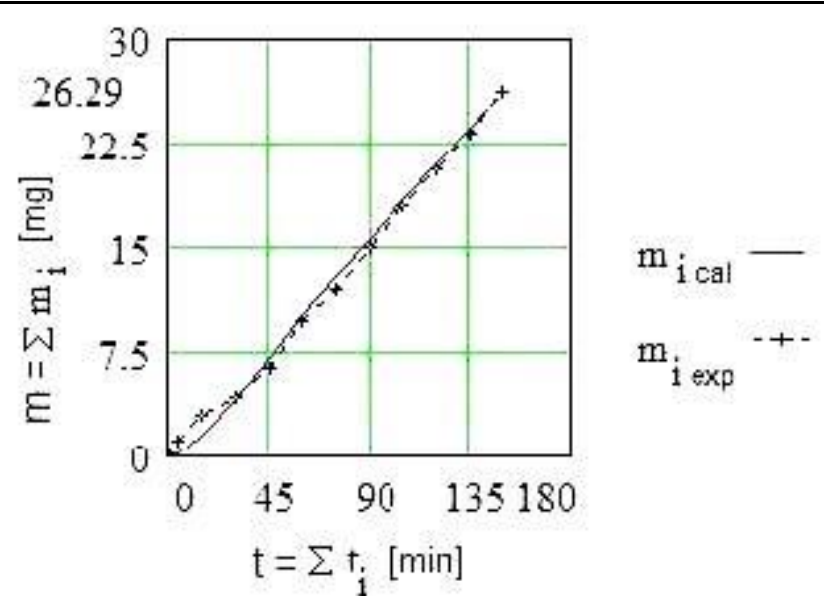

The sample without cycle of fatigue carried out

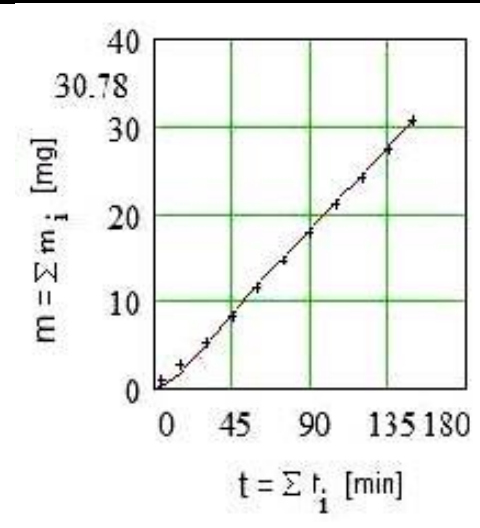

The sample with the cycle of fatigue carried out with $\Delta \sigma=170 \mathrm{MPa}$

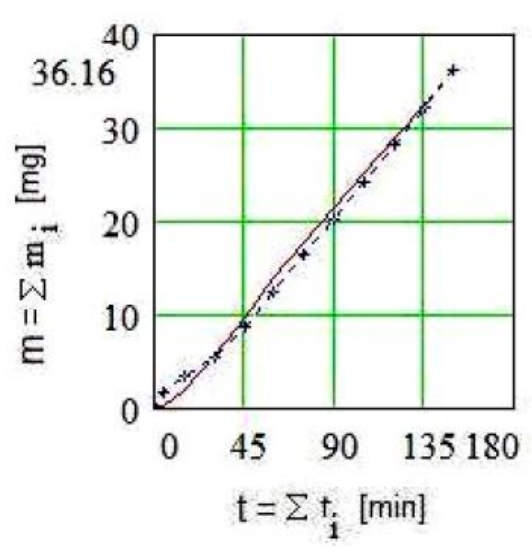

The sample with the cycle of fatigue carried out with $\Delta \sigma=226 \mathrm{MPa}$

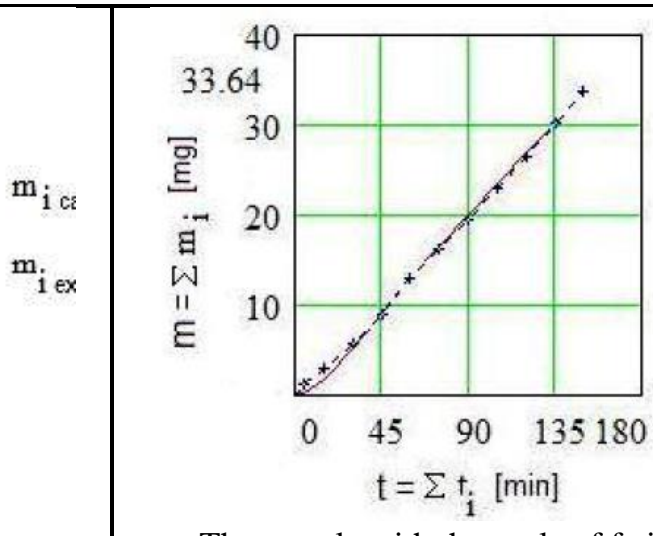

$\mathrm{m}_{\mathrm{i}}$

$\mathrm{m}_{i \in}$

The sample with the cycle of fatigue carried out with $\Delta \sigma=198 \mathrm{MPa}$
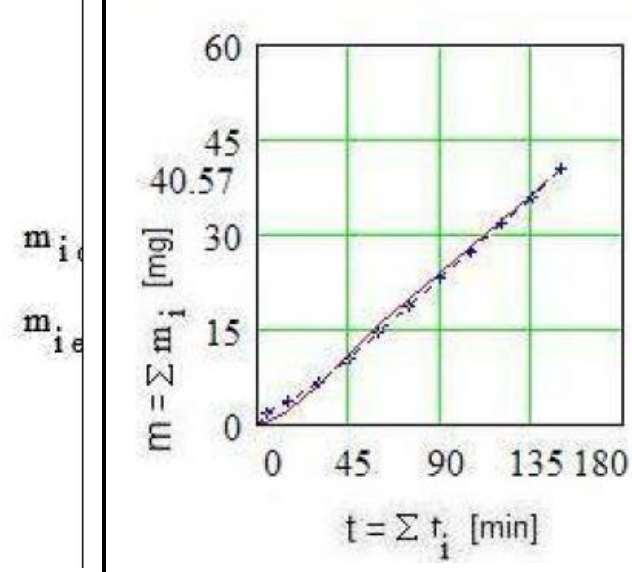

$\mathrm{m}_{\mathrm{ic}}$

$m_{i \text { ex }}$

The sample with the cycle of fatigue carried out with $\Delta \sigma=255 \mathrm{MPa}$

Figure 8. Evolution of the mass loss 
In Table 5, we notice the variations of the values for the scale parameter A and constancy for the shape parameter B. The fact that the shape parameters B have the same values (0.53) reveals that the evolution of the cavitation erosion for steel G-X5CrNi 13.4 is similar regardless of its state (with or without fatigue). The difference between the values of the parameter of scale A for samples with and without fatigue stresses expresses a reduction in the resistance of steel to the cavitation attack when it was subjected to fatigue. This reduction with the increase in the amplitude of effort is caused particularly by the increase in the level of the residual effort of the surface exposed to the cavitation attack.

The approach of the experimental results by the analytical curve proposed (relation 1) is adequate for all the types of samples (Fig. 8) with a better smoothing when it is about $\Delta \sigma=170 \mathrm{MPa}$ and $\Delta \sigma=198 \mathrm{MPa}$. This observation suggests that the distribution of the residual tensions is more homogeneous in the case of $226 \mathrm{MPa}$ and $255 \mathrm{MPa}$ loads and in the case of the material not subjected to fatigue.

We observed that the correlation of the mass loss with time and the parameter of scale A with the amplitude of $\Delta \sigma$ stress is the same type of exponential equation (Fig. 9). The difference between these functions is the parameter A. This fact will define the dependence of the parameter of scale $\mathrm{A}$ of the amplitude of the $\Delta \sigma$ effort.

$$
A(\Delta \sigma)=1,753+1,753 \cdot \Delta \sigma_{j}\left(1-e^{-77 \cdot 10^{-7 \cdot \Delta \sigma_{j}}}\right)
$$

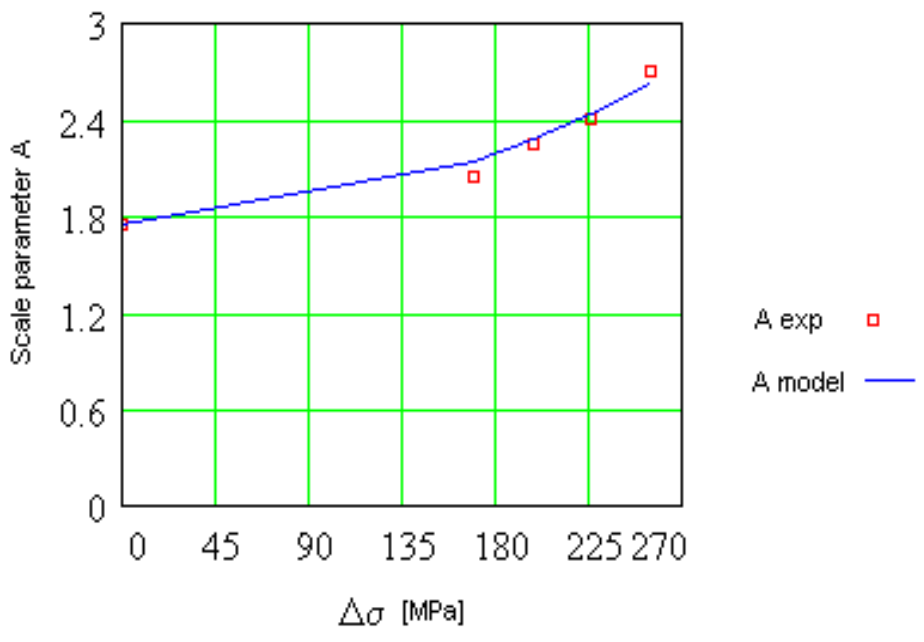

Figure 9. Correlation between mass loss and the fatigue stress level

\section{Conclusions}

- Having the same mechanism as the fatigue, the cavitation erosion is accentuated when the material is subjected to both stresses.

- The cavitation erosion mass losses are aggravated with the increase of the fatigue stress amplitude.

- The fatigue also increases the penetration depth of erosion.

- The angle of the linear sector of the characteristic curves (mass loss against time) increases with the amplitude of the fatigue stress.

- The period after which erosion becomes stable is shorter for the samples subject to fatigue than for the ones not subject of fatigue.

- Regardless of the specimens being or not subject of fatigue stresses, the evolution in time of cavitation erosion can be described by the same exponential equation.

- The scale parameter A of the exponential equation depends on the $\Delta \sigma$ fatigue stress amplitude.

\section{References}

[1] S. Kocanda, Fatigue Failure of Metals. Alphen aan den Rijn: Sijthoff \& Noordhoff International Publishers, 1978.

[2] S. M. Ahmed, K. Hokkirigawa, Y. Ito, y R. Oba, "Scanning electron microscopy observation on the incubation period of vibratory cavitation erosion", Wear, vol. 142, núm. 2, pp. 303-314, mar. 1991. doi: 10.1016/0043-1648(91)90171-P 
[3] S.M. Ahmed, K. Hokkirigawa, K. Kikuchi, Y. Matsudaira, R. Oshima, R. Oba, "Marked surfaceroughness effects on the development of microfracture during the incubation period of vibratory cavitation erosion," in Proc. 3rd Japan-China Joint Conference, Osaka, Japan, 1990, I, pp. 331.

[4] S.M. Ahmed, K. Hokkirigawa, R. Oba and K. Kikuchi, "SEM Observation of the Vibratory CavitationFracture Mode during the Incubation Period and the Small Roughness Effect," JSME international journal. Ser. 2, Fluids engineering, heat transfer, power, combustion, thermophysical properties, vol. 34, núm. 3, pp. 298-303, 1991. doi: 10.1299/jsmeb1988.34.3_298

[5] T. Okada y Y. Iwai, "Cavitation Erosion", JSME Int. journal. Ser. 1, Solid Mech. strength Mater., vol. 33, núm. 2, pp. 128-135, 1990. doi: 10.1299/jsmea1988.33.2_128

[6] W. Będkowski, G. Gasiak, C. Lachowicz, A. Lichtarowicz, T. Łagoda, y E. Macha, "Relations between cavitation erosion resistance of materials and their fatigue strength under random loading," Wear, vol. 230, núm. 2, pp. 201-209, 1999. doi: 10.1016/S00431648(99)00105-2

[7] K. S. Min, K. J. Kim, y S. W. Nam, "Investigation of the effect of the types and densities of grain boundary carbides on grain boundary cavitation resistance of AISI 321 stainless steel under creep-fatigue interaction," $J$. Alloys Compd., vol. 370, núm. 1, pp. 223-229, 2004. doi: 10.1016/j.jallcom.2003.09.129

[8] H. U. Hong, B. S. Rho, y S. W. Nam, "A study on the crack initiation and growth from $\delta$-ferrite/ $\gamma$ phase interface under continuous fatigue and creep-fatigue conditions in type 304L stainless steels," Int. J. Fatigue, vol. 24, núm. 10, pp. 1063-1070, 2002. doi: 10.1016/S0142-1123(02)00019-1

[9] A. Karimi y F. Avellan, "Comparison of erosion mechanisms in different types of cavitation," Wear, vol. 113, núm. 3, pp. 305-322, 1986. doi: 10.1016/00431648(86)90031-1

[10] C. Kanchanomai, Y. Miyashita, y Y. Mutoh, "Strain-rate effects on low cycle fatigue mechanism of eutectic $\mathrm{Sn}-\mathrm{Pb}$ solder," Int. J. Fatigue, vol. 24, núm. 9, pp. 987-993, 2002. doi: 10.1016/S0142-1123(02)000117

[11] S. M. Ahmed, K. Hokkirigawa, Y. Ito, y R. Oba, "Scanning electron microscopy observation on the incubation period of vibratory cavitation erosion", Wear, vol. 142, núm. 2, pp. 303-314, 1991. doi: 10.1016/00431648(91)90171-P

[12] Standard Test Method for Cavitation Erosion Using Vibratory Apparatus, ASTM G32-03, 2018.

[13] G. Mesmacque, M. Voda, I. Bordeasu y T. Abderrahim, "Relations statistiques d'estimation des caractéristiques de l'érosion de cavitation pour les aciers alliés," Matériaux Tech., vol. 89, núm. 9, 2001. doi: 10.1051/mattech/200189090011 